чение Culicidae в 20-30-е годы XX в. сделали А. А. Штакельберг и А. С. Мончадский, а начиная с пятидесятых годов, - А. К. Шевченко, А. В. Гуцевич, Н. С. Прудкина, И. А Виноград, М. С. Дудкина. Огромный вклад в изучение кулицид Украины сделал В. П. Шеремет, который определил для Украинского Полесья 41 вид из шести родов. На современном этапе исследованием комаров региона занимаются Ю. В. Дубровский, Л. Д. Дубровская, В. Ф. Ясинская, С. В. Корж, Н. П. Килочицкая.

Ключевые слова: кровососущие комары, видовой состав, фауна, Украинское Полесье.

Oleksandr Levitskyi. History of Research of Mosquitos in Ukrainian Polissya. The modern condition of studing of mosquitos in Ukrainian Polissya has been analysed. The research of mosquitos in this region last for more than 90 years. O. Stackelberg, O. Monchadskyi, A. Hutsevych, H. Shevchenko, N. Prudkina, V. Sheremet, I. Vynohrad, M. Dudkina have made contribution in the studying of mosquitos in the 20th and 30th years of the twentieth century. H. Shevchenko, N. Prudkina, V. Sheremet, I. Vynohrad, M. Dudkina have made contribution in the studying of mosquitos in the 60th and 70th years of the twentieth century. V. Sheremet have made a great contribution in the studying of mosquitos in the 90th years of the twentieth century. V. Sheremet determined to Ukrainian Polissya 41 species of 6 families. I. Dubrovskyi, L. Dubrovska, V. Yasynska, Z. Korzh, N. Kilochytska carried out the research of mosquitos in the region.

Key words: mosquito, the species composition, fauna, Ukrainian Polissya.

Стаття надійшла до редколегії 02.09.2016 р.

УДК 574.2 (595.76)

Максим Чумак

\title{
Сапроксилобіонтні твердокрилі (Coleoptera, Insecta) й мертва деревина в буковому пралісі Угольського масиву Карпатського біосферного заповідника
}

Вплив мертвої деревини на чисельність та якісний склад сапроксилобіонтних твердокрилих вивчали методом обліку комбінованими пастками на 60 пробних площах у межах висот 650-830 метрів над рівнем моря. Опрацьовано 40241 особину. Видове багатство та динамічна щільність сапроксилобіонтних твердокрилих прямо корелюють з об'ємами мертвої деревини в буковому пралісі. Домінуючими індикаторними видами на першій стадії розкладу деревини є Anoplodera sexguttata (Fabr.) - 1,26 \% (Cerambycidae) та Hylecoetus dermestoides (L.) - 1,02 \% (Lymexylidae); домінуючі види-індикатори другої стадії - Silvanus bidentatus (Fabr.) $1,02 \%$ (Silvanidae); домінуючі види-індикатори третьої стадії - Taphrorychus bicolor (Herbst) - 1,59 \% (Curculionidae) та Isoriphis melasoides (Laporte) - 1,01 \% (Eucnemidae); домінуючі види-індикатори четвертої й п’ятої стадій - Osphya bipunctata (Fabr.) - 1,1-1,2 \% (Melandryiidae) та Mycetophagus ater (Reitter) - 1,01 \% (Mycetophagidae).

Ключові слова: сапроксилобіонтні твердокрилі, мертва деревина, буковий праліс.

Постановка наукової проблеми та її значення. Букові праліси є осередками багатьох видів тварин, розвиток яких відбувається у відмерлій деревині. Вік дерев першого ярусу лісової екосистеми Угольського масиву Карпатського біосферного заповідника оцінюють у 270-350 років. Упродовж цього періоду деревостан зазнає перманентних змін, оскільки простежено постійний відпад дерев, на місці яких відбувається його відновлення. У буковому пралісі виділяють шість стадій розвитку: нового покоління (тривалість - 20-40 років), молодняку (40-60 років), жердняку (60-80 років), пристигання (6080 років), стиглості (40-60 років) і розпаду (40-60 років) [4; 5]. Процес розкладу деревини відбувається в часових межах розвитку нового покоління [1]. Упродовж цього періоду закономірно змінюються сукцесії комах - сапроксилобіонтів.

Стадія нового покоління формується, зазвичай, на місці вивалів старих дерев, які випадають із першого ярусу деревостану в результаті вітровалу або сніголому. Таке накопичення великої кількості мертвої деревини утворює передумови для розвитку сапроксилобіонтних видів комах, у тому числі жуків. Зокрема, для букових пралісів Угольського масиву Карпатського біосферного заповідника відомо 335 видів сапроксилобіонтних твердокрилих (Coleoptera) [3].

(C) Чумак M., 2016 
Мета дослідження - пошук відповіді на питання щодо того, як корелює кількість та якість відмерлої деревини в буковому пралісі з видовим багатством і динамічною щільністю сапроксилобіонтних твердокрилих на стадії розвитку нового покоління; які види домінують в угрупованнях сапроксилобіонтних твердокрилих на різних стадіях розкладу деревини.

Матеріал та методика досліджень. Вплив мертвої деревини на чисельність і якісний склад сапроксилобіонтних твердокрилих вивчали методом обліку на 60 пробних площах (ПП), просторово об'єднаних у 20 пробних ділянок у межах висот 650-830 м над рівнем моря Угольського масиву Карпатського біосферного заповідника. Центром пробної ділянки був центр галявини, що утворилася в результаті вивалу дерев першого ярусу. На кожній пробній ділянці виділено по три пробні площі, на яких установлено по одній комбінованій пастці для відлову комах. Комбіновані пастки - лійки жовтого кольору діаметром 40 см із встановленими над ними прозорими пластинами з оргскла. Детально будову комбінованих пасток описано в роботі [3], тому схему будови пасток тут не наводимо. Пастки функціонували протягом вегетаційних періодів із 01 травня по 30 вересня у 2011 та 2012 pр. (двохрічні збори). Аналіз грунтується на опрацюванні 40241 особини твердокрилих.

Облік мертвої деревини проводили за методикою J. Böhl, U.-B. Brändli [2; 6].

Ступінь розкладу мертвої деревини для стоячих і лежачих деревних стовбурів установлювали за відносною твердістю деревини з допомогою кишенькогового ножа за методикою [2]. За нею можна приблизно встановити час відмирання дерева. При цьому, згідно з методикою, виділяли п'ять категорій (цит. за [2]): «1. Свіжа деревина (ніж майже не проникає в деревину); 2. Тверда мертва деревина (деревина тверда; ніж важко проникає у напрямку волокон деревини); 3. Прогнила мертва деревина (менш тверда, ніж 2; ніж легко проникає у напрямку волокон (більше 1 см в глибину дерева), але не проникає перпендикулярно (впоперек) напрямку волокон деревини); 4. Трухлява мертва деревина (м'яка; ніж легко проникає також перпендикулярно до напрямку волокон на глибину більше 1 см); 5. Порохнява мертва деревина (дуже м'яка або порохнява деревина; ледве тримається разом)».

Ураховуючи, що в чистих букових пралісах деревина товстих буків розкладається впродовж 1030 років і більше [1, с. 285], перша стадія для лежачої мертвої деревини (стовбурів бука), на нашу думку, може тривати 1-2 роки, друга $-3-5$ років, третя $-3-5$ років, четверта $-5-10$ років, п'ята понад 20 років. Для стоячих стовбурів тривалість стадій більша.

Виклад основного матеріалу й обгрунтування отриманих результатів дослідження. Середні значення показників об'ємів мертвої деревини, кількість облікованих особин та видів, розраховані для кожної пробної площі (ПП), наведено в табл. 1. Середнє значення для мертвої деревини на одну пробну площу становить 152,9 м³/га, мінімальне - 2,0, максимальне - $636 \mathrm{~m}^{3} /$ га (рис. 1). Середня кількість особин у перерахунку на одну пробну площу - 681,18, максимум - 1739,0, мінімум - 212,0 (рис. 2). Видове багатство: середнє значення - 80,17 видів, максимум - 118,0 видів, мінімум - 63,0 (рис. 3).

Таблиця 1

\section{Результати обліків об’смів мертвої деревини, кількості особин та видів твердокрилих у перерахунку на одну пробну площу $(n=60)$}

\begin{tabular}{|l|c|c|c|}
\hline \multicolumn{1}{|c|}{ № 3/п } & $\begin{array}{c}\text { Об’см мертвої деревини, } \\
\boldsymbol{м}^{3} / z \boldsymbol{~} \text { на ПП }\end{array}$ & $\begin{array}{c}\text { Кількість особин на ПП } \\
\text { (динамічна щільність) }\end{array}$ & $\begin{array}{c}\text { Кількість видів на ПП } \\
\text { (видове багатство) }\end{array}$ \\
\hline $\mathrm{x}_{ \pm} \mathrm{m}_{\mathrm{x}}$ & $152,85 \pm 122,89$ & $681,18 \pm 254,52$ & $80,16 \pm 8,33$ \\
\hline $\mathrm{x}_{\min }$ & 2,0 & 212,0 & 63,0 \\
\hline $\mathrm{x}_{\max }{ }^{1}$ & 636,0 & 1739,0 & 118,0 \\
\hline
\end{tabular}

Оскільки мертва деревина - оселище для сапроксилобіонтних видів комах, зокрема жуків, то логічно було б припустити, що іiї об'м корелюватиме як із видовим багатством, так і $з$ кількістю видів (динамічною щільністю). Аналіз отриманих даних підтвердив цю тезу. Кількість особин і видів свідчить про позитивну кореляцію з об' ємами мертвої деревини на пробних площах: із динамічною щільністю (кількість особин) кореляція помірна й пряма (r=0,4; коефіцієнт кореляції статистично

\footnotetext{
${ }^{1} X_{ \pm} m_{x}-$ середнє значення й стандартне відхилення; $\min -\max$ - ліміти параметра.
} 
значущий), із видовим багатством (кількістю видів) кореляція слабка та пряма (r=0,051; коефіцієнт кореляції статистично не значущий) (рис. 4-7).

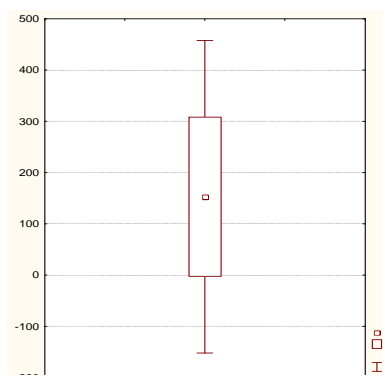

Рис. 1. Розмах показників запасів мертвої деревини на одну пробну плошу

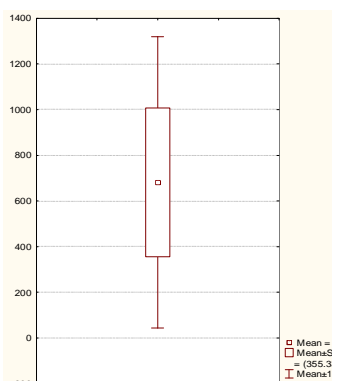

Рис. 2. Розмах показників кількості особин на одну пробну площу

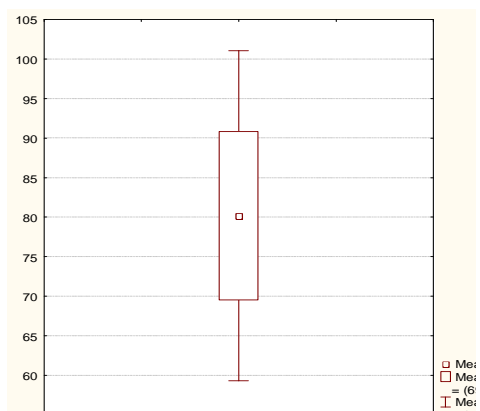

Рис. 3. Розмах показників кількості видів на одну пробну площу

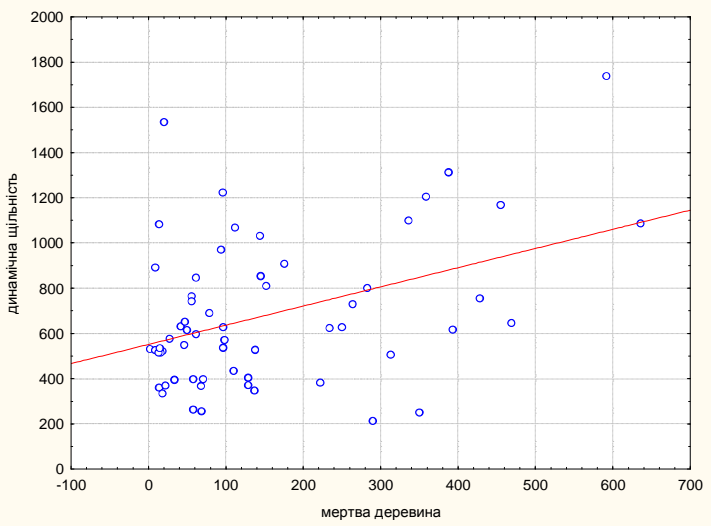

Рис. 4. Корелячія між кількістю мертвої деревини й динамічною щільністю $(r=0,4 ; p<0,05)$

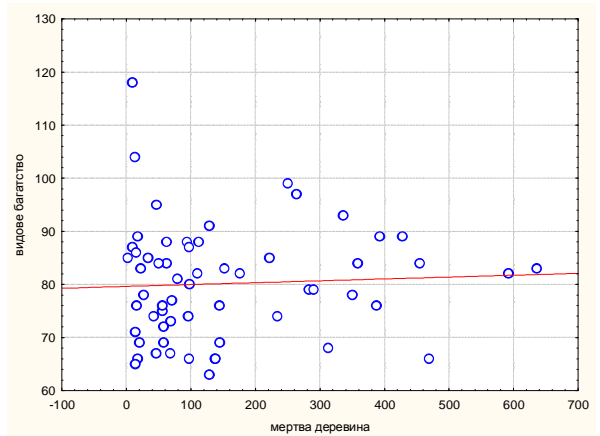

Рис. 6. Кореляція між кількістю мертвої деревини й видовим багатством $(r=0,051 ; p>0,05)$

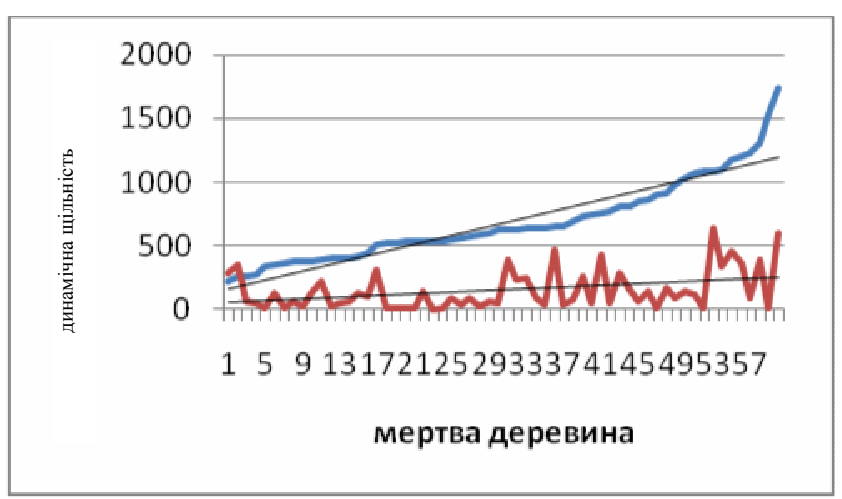

Рис. 5. Графік зміни щільлності особин сапроксилобіонтних твердокрилих при зростанні об'сму мертвої деревини

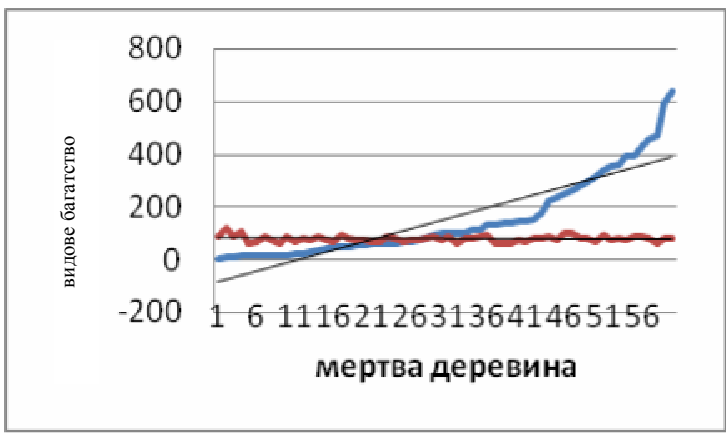

Рис. 7. Графік зміни видового багатства сапроксилобіонтних твердокрилих при зростанні об' 'му мертвої деревини

Стадії розкладу деревини. Важливою для фауністичного різноманіття комах, пов'язаних у своєму розвитку з мертвою деревиною, $є$ і їі якість, тобто ступінь її розкладу. На пробних площах нами виділено всі п'ять стадій розкладу (див. методику, табл. 2). Оскільки різні стадії розкладу деревини виявлено на різних за кількістю площах, усі розрахунки проводимо в перерахунку на одну пробну площу (ПП). 
Об'єми мертвої деревини та показники різноманіття на пробних площах із різними стадіями розкладу мертвої деревини

\begin{tabular}{|l|c|c|c|c|c|}
\hline & \multicolumn{5}{|c|}{ Стадія розкладу деревини } \\
\hline & 1 & 2 & 3 & 4 & 5 \\
\hline Кількість ПП & 9 & 11 & 12 & 14 & 14 \\
\hline $\begin{array}{l}\text { Об'єм мертвої } \\
\text { деревини } \\
\left(\text { на 1 ПП) }\left(X \pm m_{x}\right)^{1}\right.\end{array}$ & $191,33 \pm 206,77$ & $106,56 \pm 77,47$ & $178,75 \pm 206,03$ & $154,86 \pm 167,81$ & $143,85 \pm 106,77$ \\
\hline $\begin{array}{l}\text { Кількість видів } \\
\left(\text { на 1 ПП) }\left(X \pm m_{x}\right)\right.\end{array}$ & $80,56 \pm 16,85$ & $79,45 \pm 10,47$ & $83,75 \pm 11,46$ & $79,43 \pm 8,69$ & $78,14 \pm 7,12$ \\
\hline $\begin{array}{l}\text { Кількість особин } \\
\text { (на 1 ПП) }\left(X \pm m_{x}\right)\end{array}$ & $968,0 \pm 311,25$ & $614,18 \pm 257,41$ & $597,33 \pm 218,69$ & $695,07 \pm 435,04$ & $1108,5 \pm 265,75$ \\
\hline
\end{tabular}

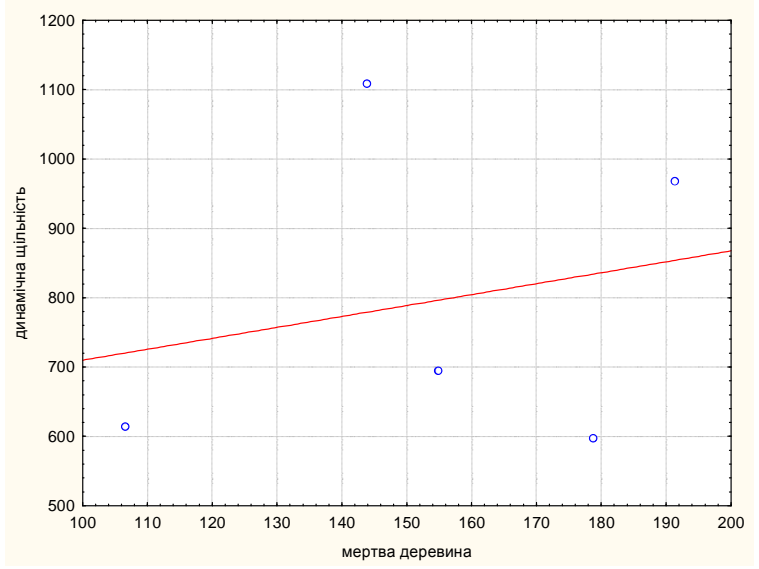

Рис. 8. Кореляція між кількістю мертвої деревини й динамічною щзільністю (кількістю особин) на різних стадіях розкладу $\left(r_{x y}=0,0282\right)(p>0,05)$. Зв'язок міжс ознакою Ү і фактором Х слабкий і прямий. Коефімієнт кореляиії статистично не значущий

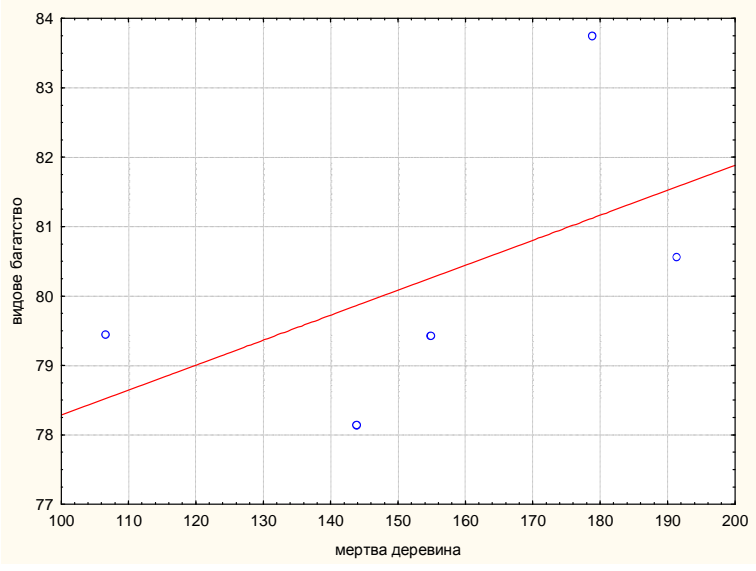

Рис. 9. Кореляція між кількістю мертвої деревини й кількістю видів (видовим багатством) на різних стадіях розкладу мертвої деревини $\left(r_{x y}=0,558\right)$ ( $p>0,05)$. Зв'язок між ознакою $Y$ і фактором $X$ помітний і прямий. Коефіиієнт корелячії статистично не значущий

Розрахунки свідчать, що між кількістю мертвої деревини й динамічною щільністю особин або видовим багатством кореляція слабка, хоча й позитивна (рис. $8 ; 9$ ).

Табл. 3 презентує домінуючі види на ділянках різних стадій розкладу деревини. Оцінку проведено для видів, частка яких у вибірках становила понад $1 \%$ (еудомінанти, домінанти, субдомінанти). Із таблиці видно, що таких видів 12-17 на ділянку при загальній їх кількості 23. При цьому загальна кількість особин цих видів у сумі становить 75-80 \% від усієї кількості особин. У цьому випадку ігноруються види-субрецеденти $(\mathrm{Pi}<0,1)$.

Таблиия 3

Домінуючі види твердокрилих на різних стадіях розкладу деревини

\begin{tabular}{|c|c|c|c|c|c|c|}
\hline \multirow{2}{*}{$\begin{array}{c}\text { № } \\
\text { 3/II }\end{array}$} & \multirow[t]{2}{*}{ Домінуючі види (Pi>1 \%) } & \multicolumn{5}{|c|}{$\begin{array}{c}\text { Частка видів в угрупованнях на різних стадіях } \\
\text { розкладу }(P i)(\%)\end{array}$} \\
\hline & & 1 стадія & 2 стадія & 3 стадія & 4 стадія & 5 стадія \\
\hline 1 & 2 & 3 & 4 & 5 & 6 & 7 \\
\hline 1 & Dasytes plumbeus (Müller, 1776) & 25,71 & 18,24 & 16,69 & 20,66 & 22,80 \\
\hline 2 & Cychramus luteus (Fabricius, 1787) & 21,77 & & 8,52 & 11,81 & 12,96 \\
\hline 3 & Judolia cerambyciformis (Schrank, 1781) & 13,69 & 13,53 & 17,56 & 16,43 & 15,16 \\
\hline 4 & Pediacus dermestoides (Fabricius, 1792) & 4,29 & 4,71 & 4,52 & 3,25 & 3,95 \\
\hline
\end{tabular}

\footnotetext{
${ }^{1} X \pm m_{x}-$ середнє значення й стандартне відхилення.
} 
РОЗДІЛ ІІ. Зоологія. 12, 2016

Закінчення таблииі 3

\begin{tabular}{|c|c|c|c|c|c|c|}
\hline 1 & 2 & 3 & 4 & 5 & 6 & 7 \\
\hline 5 & Alosterna tabacicolor (De Geer, 1775) & 4,03 & 3,74 & 3,10 & 4,83 & 2,61 \\
\hline 6 & Anaspis pulicaria Costa, 1854 & 3,39 & 4,50 & 3,07 & 4,61 & 3,20 \\
\hline 7 & Xyleborinus saxesenii (Ratzeburg, 1837) & 1,71 & 4,38 & 2,66 & 1,89 & 1,70 \\
\hline 8 & Epuraea rufomarginata (Stephens, 1832) & 1,33 & 8,94 & 6,56 & 5,09 & 5,58 \\
\hline 9 & Anaspis thoracica (Linnaeus, 1758) & 1,02 & 1,12 & 1,90 & 1,58 & 1,56 \\
\hline 10 & Anoplodera sexguttata (Fabricius, 1775) & 1,26 & & & & \\
\hline 11 & Epuraea silacea (Herbst, 1784) & 1,13 & 1,75 & 1,16 & 1,57 & \\
\hline 12 & Cychramus variegatus (Herbst, 1792) & & 9,71 & 1,44 & 1,76 & \\
\hline 13 & Hylecoetus dermestoides (Linnaeus, 1861) & 1,02 & & & & \\
\hline 14 & Denticollis linearis (Linnaeus, 1758) & & 1,095 & & 1,15 & 1,37 \\
\hline 15 & Silvanus bidentatus (Fabricius, 1792) & & 1,02 & & & \\
\hline 16 & Anaspis flava (Linnaeus, 1758) & & & 1,51 & 1,10 & 1,11 \\
\hline 17 & Anaspis frontalis (Linnaeus, 1758) & & & 1,51 & 1,18 & 1,12 \\
\hline 18 & Mycetophagus quadripustulatus (Linnaeus, 1761) & & 1,23 & 2,05 & 1,62 & 1,28 \\
\hline 19 & Osphya bipunctata (Fabricius, 1775) & & & & 1,10 & 1,21 \\
\hline 20 & Ptilinus pectinicornis (Linnaeus, 1758) & & 1,49 & 1,83 & 1,31 & 1,44 \\
\hline 21 & Taphrorychus bicolor (Herbst, 1793) & & & 1,59 & & \\
\hline 22 & $\begin{array}{l}\text { Isoriphis melasoides (Laporte de Castelnau, } \\
1835 \text { ) }\end{array}$ & & & 1,01 & & \\
\hline 23 & Mycetophagus ater (Reitter, 1879) & & & & & $\mathbf{1 , 0 1}$ \\
\hline & Кількість видів: & 12 & 14 & 17 & 17 & 16 \\
\hline & Усього, \% & 80,35 & 75,46 & 76,67 & 80,95 & 78,06 \\
\hline
\end{tabular}

Численними (фоновими) на всіх стадіях розкладу є дев'ять видів: Dasytes plumbeus (Müll.) (Dasytidae), Judolia cerambyciformis (Schr.) (Cerambycidae), Alosterna tabacicolor (DeG.) (Cerambycidae), Anaspis pulicaria Costa (Scraptiidae), Anaspis thoracica (L.) (Scraptiidae), Pediacus dermestoides (Fabr.) (Cucujiidae), Xyleborinus saxesenii (Ratz.) (Curculionidae), Epuraea rufomarginata (Steph.) (Nitidulidae), Cychramus luteus (Fabr.) (Nitidulidae). Ці види беруть участь у розкладі деревини на різних стадіях.

3 інших 12 видів, які входять до списку, Anoplodera sexguttata (Fabr.) - 1,26 \% (Cerambycidae) та Hylecoetus dermestoides (L.) - 1,02 \% (Lymexylidae) можна вважати індикаторами першої стадії розкладу; Silvanus bidentatus (Fabr.) - 1,02 \% (Silvanidae) - індикатором другої стадії; Taphrorychus bicolor (Herbst) - 1,59\% (Curculionidae) та Isoriphis melasoides (Laporte) - 1,01 \% (Eucnemidae) - третьої стадії. Індикатори четвертої й п'ятої стадій - Osphya bipunctata (Fabr.) - 1,1-1,2 \% (Melandryiidae) i Mycetophagus ater (Reitter) - 1,01\% (Mycetophagidae).

За своїм місцем у сукцесіях угруповань комах - деструкторів деревини - Hylecoetus dermestoides (L.) входить до угруповання на лімексилоїдній стадії розкладу деревини, Anoplodera sexguttata (Fabr.) та Isoriphis melasoides (Laporte) - на церамбіцидній стадії, Osphya bipunctata (Fabr.) і Mycetophagus ater (Reitter) - на луканідній; Silvanus bidentatus (Fabr.) - пірохроїдній, Taphrorychus bicolor (Herbst) сколітидній стадії розкладу кори.

Висновки й перспективи подальшого дослідження. Видове багатство сапроксилобіонтних твердокрилих засвідчує позитивну слабку й пряму кореляцію з об'ємами мертвої деревини в буковому пралісі Угольського масиву (r=0,051; коефіцієнт кореляції статистично не значущий).

Динамічна щільність сапроксилобіонтних твердокрилих Угольського масиву позитивно корелює 3 об' ємами мертвої деревини: кореляція помірна та пряма ( $\mathrm{r}=0,4$; коефіцієнт кореляції статистично значущий).

Домінуючими (фоновими) видами сапроксилобіонтних видів твердокрилих Угольського масиву Карпатського біосферного заповідника на всіх стадіях розкладу деревини є дев'ять видів: Dasytes plumbeus (Müll.) (Dasytidae) (рясність $\mathrm{Pi}=16,69-25,71 \%$ \%); Judolia cerambyciformis (Schr.) (Cerambycidae) ( $\mathrm{Pi}=13,69-17,56 \%)$, Alosterna tabacicolor (DeG.) (Cerambycidae) $(\mathrm{Pi}=3,1-4,83 \%)$, Anaspis pulicaria Costa (Scraptiidae) (Pi =3,07-4,61\%), Anaspis thoracica (L.) (Scraptiidae) (Pi =1,02-1,9 \%), Pediacus dermestoides (Fabr.) (Cucujiidae) ( $\mathrm{Pi}=3,25-4,71 \%)$, Xyleborinus saxesenii (Ratz.) (Curculionidae) 
( $\mathrm{Pi}=1,70-4,38 \%$ ), Epuraea rufomarginata (Steph.) (Nitidulidae) ( $\mathrm{Pi}=1,33-8,94 \%)$, Cychramus luteus (Fabr.) (Nitidulidae) (Pi =8,52-21,77 \%). Ці види беруть участь у розкладі деревини на різних стадіях.

Домінуючими індикаторними видами на першій стадії розкладу деревини є Anoplodera sexguttata (Fabr.) - 1,26\% (Cerambycidae) та Hylecoetus dermestoides (L.) - 1,02 \% (Lymexylidae); домінуючі види-індикатори другої стадії - Silvanus bidentatus (Fabr.) - 1,02 \% (Silvanidae); домінуючі види-індикатори третьої стадії - Taphrorychus bicolor (Herbst) - 1,59\% (Curculionidae) та Isoriphis melasoides (Laporte) - 1,01 \% (Eucnemidae); домінуючі види-індикатори четвертої та п'ятої стадій - Osphya bipunctata (Fabr.) - 1,1-1,2 \% (Melandryiidae) i Mycetophagus ater (Reitter) - 1,01 \% (Mycetophagidae).

За своїм місцем у сукцесіях угруповань комах - деструкторів деревини Hylecoetus dermestoides (L.) входить до угруповання на лімексилоїдній стадії розкладу деревини, Anoplodera sexguttata (Fabr.) i Isoriphis melasoides (Laporte) - на церамбіцидній стадії, Osphya bipunctata (Fabr.) та Mycetophagus ater (Reitter) - на луканідній стадії розкладу деревини; Taphrorychus bicolor (Herbst) - на сколітидній, Silvanus bidentatus (Fabr.) - пірохроїдній стадії розкладу кори.

\section{Джерела та література}

1. Екологія грибів / Г. Л. Антоняк, 3. І. Калинець- Мамчур, І. О. Дудка, Н. О. Бабич, Н. Є. Панас. - Львів : [б. в.], 2013. -628 с.

2. Методичні вказівки зі статистичної інвентаризації Угольсько-Широколужанського букового пралісу / Рафаела Тіннер, Брігітте Коммармот, Петер Бранг, Урс-Беат Брендлі; Швейцарський федеральний ін-т дослідж. лісу, снігу і ландшафтів WSL. - Бірменсдорф, 2010. - 65 с.

3. Таксономічний склад сапроксилобіонтних твердокрилих (Insecta, Coleoptera) Угольського масиву фауни Карпатського біосферного заповідника / М. В. Чумак, О. Ю. Мателешко, В. О. Чумак [та ін.] // Науковий вісник Ужгородського університету. - Серія «Біологія». - Вип. 38-39. - 2015. - С. 5-11.

4. Шпарик Ю. С. Структура букових пралісів Українських Карпат на основних стадіях їх сукцесії / Ю. С. Шпарик // Лісове господарство, лісова, паперова і деревообробна промисловість. - № 31. Львів, 2006.- С. 144-150.

5. Шпарик Ю. С. Структура букового пралісу Українських Карпат / Ю. С. Шпарик, Б. Коммармот, Ю. Ю. Беркела. - Снятин : Вид-во «Прут-принт», 2010. - 143 с.

6. Böhl J. Deadwood volume assessment in the third Swiss National Forest Inventory: methods and first results / J. Böhl, U.-B. Brändli // Eur. J. Forest Res. - № 126. - 2007. - P. 449-457.

Чумак Максим. Сапроксилобионтные жесткокрылые (Coleoptera, Insecta) и мертвая древесина в буковом пралесе Угольского массива Карпатского биосферного заповедника. Влияние мертвой древесины на численность и качественный состав сапроксилобионтных жесткокрылых изучали методом учета комбинированными ловушками на 60 пробных площадках на высотах 650-830 м над уровнем моря. Изучено 40241 особь. Видовое богатство и динамическая плотность сапроксилобионтных жесткокрылых прямо коррелируют с объемами мертвой древесины в буковом пралесе. Доминирующими индикаторными видами на первой стадии деструкции древесины являются Anoplodera sexguttata (Fabr.) - 1,26 \% (Cerambycidae) и Hylecoetus dermestoides (L.) - 1,02 \% (Lymexylidae); доминирующие виды-индикаторы второй стадии - Silvanus bidentatus (Fabr.) - 1,02 \% (Silvanidae); доминирующие виды-индикаторы третьей стадии - Taphrorychus bicolor (Herbst) - 1,59 \% (Curculionidae) и Isoriphis melasoides (Laporte) - 1,01 \% (Eucnemidae); доминирующие виды-индикаторы четвертой и пятой стадий Osphya bipunctata (Fabr.) - 1,1-1,2 \% (Melandryiidae) и Mycetophagus ater (Reitter) - 1,01 \% (Mycetophagidae).

Ключевые слова: сапроксилобионтные жесткокрылые, мертвая древесина, буковый пралес.

Chumak Maksym. Saproxylic Beetles (Coleoptera, Insecta) and Dead Wood in Beech Virgin Forests Uholka Massif Carpathian Biosphere Reserve. Effect of dead wood on number and quality of the saproxylic beetles studied accounting method by combined traps on 60 sampling plots at altitudes of 650-830 meters above sea level. 40241 individuals studied.

Species richness and dynamic density of saproxylic beetles directly correlated with the volume of dead wood in beech virgin forests. The dominant indicator species in the first stage of destruction of wood are Anoplodera sexguttata (Fabr.) - 1,26\% (Cerambycidae) and Hylecoetus dermestoides (L.) - 1,02 \% (Lymexylidae); dominant indicator species of the second stage - Silvanus bidentatus (Fabr.) - 1,02\% (Silvanidae); dominant indicator species of the third stage Taphrorychus bicolor (Herbst) - 1,59 \% (Curculionidae) and Isoriphis melasoides (Laporte) - 1,01 \% (Eucnemidae); the dominant species-indicators of the fourth and fifth stages - Osphya bipunctata (Fabr.) - 1,1-1,2 \% (Melandryidae) and Mycetophagus ater (Reitter) - 1,01\% (Mycetophagidae).

Key words: saproxylic Coleoptera, dead wood, beech virgin forests.

Стаття надійшла до редколегії 17.09.2016 р. 